\title{
JORGE MILLAS Y EL CONOCIMIENTO COMO UNA SUSTITUCIÓN DE LA EXPERIENCIA
}

\author{
Alejandro Ramírez F. \\ Universidad de Chile \\ alramire@uchile.cl
}

\begin{abstract}
RRA De ordinario la teoría del conocimiento se articula en torno a la idea de entender cómo el sujeto explica, describe y representa el entorno, la experiencia, el mundo. El conocimiento es acerca de "lo que hay", aun cuando, para ello, apele a estructuras ideales y no directamente empíricas. La teoría del conocimiento de Jorge Millas representa una especial forma de entender esto: conocer, expresión del pensamiento racional de un sujeto que constata la existencia de un objeto, o de una clase de ellos, de sus propiedades y de sus relaciones ${ }^{1}$ (Millas 1969, Tomo I, p. 93), finalmente no trata con nuestra experiencia directa, sino que, al teorizar, la sustituye por aquello no experimentable, observable. Tal vez esta es la idea central del planteo epistemológico de Millas, porque en función de ella es posible estructurar muchos otros conceptos que dan cuenta de la cuestión del conocer: "conceptos límite"; "mundo"; "integración racional de la experiencia"; "operación del pensamiento". Una precaución: esta tesis de la sustitución está pensada por el autor más en relación con el conocimiento sistemático que para el ordinario, aunque no exclusivamente.
\end{abstract}

Pero lo conocido, como algo que está por la experiencia real, tiene su origen en la experiencia; no prescinde de ella. Parte de ella. La cuestión es que no se queda allí, sino que su función es describirnos lo que no está allí, ante nosotros. La experiencia presenta este fenómeno o este otro; es eso a lo que accedemos directamente por medio de nuestros sentidos. Pero al explicar dicha experiencia introducimos estructuras mentales, los conceptos y estructuras lógicas que permiten concebir esa experiencia primaria bajo una cierta regularidad, conceptos que, como tales, no pueden estar presentes sensorialmente ante nosotros. Es lo ontológicamente ausente. Afirma Millas:

La experiencia del hecho singular, conservada como imagen de la subjetividad y, aún más, incorporada por la memoria a la serie temporal de los recuerdos, queda así sujeta a la representación de un orden sistemático de clases y de relaciones entre clases de experiencia (Millas 1969, Tomo II, p. 364).

Y agrega, allí mismo:

Sus ideas sobre la teoría del conocimiento Millas las expone en Idea de la filosofía. El conocimiento, publicado en 1969, Editorial Universitaria, Santiago, en dos tomos. 
De este modo, también nuestro conocimiento, orientado y dirigido por el mundo real, cuya intelección y sentido incumbe a la curiosidad y a la acción del ente humano, trata con el mundo, en cada momento, mucho más en ausencia que en presencia (...) Por eso el contenido de todo pensamiento es la experiencia ausente y constituye una reconstrucción de la experiencia pasada y una anticipación de la posible. El pensamiento resulta ser, así, el sustituto de la experiencia. La experiencia misma en cuanto tal no es objeto de pensamiento: solo lo es la experiencia eventual (op. cit., p. 364).

Así se constituye lo que Millas denomina "lo ausente". Con su propio ejemplo: supongamos el enunciado El sol alumbra. Esta estructura lingüística tiene una función cognoscitiva de indicar más allá de la mera experiencia, de señalar experiencias posibles que no nos son dadas en su conjunto. Permite transitar de una experiencia dada "sol" a otra como es la de la luz y, de allí, transitar a la teorización de la relación posible entre ambas, entre la luz y la naturaleza de una estrella, de qué depende esa relación, etc. Todo esto último es lo "empíricamente ausente", pues es una totalidad inteligible, que es el objetivo de la ciencia.

Sustituir la experiencia directa por otra solo ausente, esencialmente ausente, nunca accesible sino por medio de estructuras conceptuales tiene, a primera vista, un sabor platónico. Pero, hay peligro de equivocarse en esto; Millas no es un platónico, sino solamente en un cierto aspecto. Porque no hay postulados aquí de ideas perennes ni cortes radicales entre mundos inteligibles y sensibles; por el contrario, lo que hay es una continuidad y, sobre todo, una consideración de las estructuras cognitivas organizativas de la experiencia como propiedades de la subjetividad; no como formas eternas. Lo que significa esta sustitución viene dada por Millas en relación con el rol que cumple esta concepción del conocimiento: se trata de una función de "integración de la experiencia". La experiencia directa es siempre singular; nuestro mundo se nos presenta perceptiblemente disperso, disgregado. La filosofía, es más, consiste, para Millas, en la elaboración de los conceptos ("límites") con los cuales logramos integrar aquella discontinuidad en una unidad comprensible. La filosofía es, así, "integración racional de la experiencia" (op. cit., Tomo I p. 19 y ss). Afirma Millas:

La percepción de una cosa, la imagen visual de un árbol, por ejemplo, no constituye por si sola verdadero saber. El saber supone manejo de relaciones y, por consiguiente, la integración de la experiencia en unidades que exceden su contenido actual y concreto. El auténtico saber del mundo se apoya en la experiencia, pero justo para rebasarla y alcanzar aquello que se muestra incompletamente en ella, o que, como sucede con la experiencia futura, no se muestra en absoluto (op. cit., tomo I, p. 19).

Millas representa, así, el empirismo contemporáneo, que asume la preeminencia de la experiencia, pero siempre mediada por elementos organizativos netamente subjetivos, como son lo que denomina "operaciones del pensamiento". El empirismo clásico, ilustrado, el de Locke, Hume o Berkeley, hacía descansar toda idea simple finalmente en "representaciones fuertes", en las impresiones. Pero sería un error considerar que en dicho empirismo clásico solo la experiencia era considerada como expediente del conocer, puesto que las ideas complejas, a diferencia de las simples, requieren para su 
constitución de la intervención de la subjetividad, de la imaginación, que es capaz de unir, de asociar. El empirismo nunca ha sido solamente empirismo.

La integración de la experiencia, concepto clave de Millas, tiene varios planos: la axiología, uno de los conceptos límite centrales de la filosofía, logra integrar nuestra experiencia de lo valórico en general, incluido lo ético. La integración de los objetos existentes es permitida por otro concepto de la filosofía: la ontología. Y, el tercero, es el conocimiento. Estas integraciones llegan a constituir, pues, lo que Millas denomina "mundos": el mundo humano de los valores; el mundo humano de lo que existe y el mundo del conocimiento. Mundo, pues, no significa la colección de objetos o de procesos; mundo indica aquí la red conceptual y de significados con la que el sujeto encara su entorno. Mundo, en todo caso, significa kantianamente los objetos y procesos constatables para un sujeto epistémico. Cambio de mundo, entonces, habría que interpretarlo así, como decía Kuhn casi en la misma época ${ }^{2}$ en que Millas escribe Idea de la filosofía. El conocimiento, como un cambio en las formas específicas en las que la teoría del conocimiento, en un momento determinado, integra la experiencia dispersa y ofrece entonces una imagen, un mundo, una manera en que las cosas aparecen organizadas y las entendemos organizadas.

Pero el conocimiento no es para Jorge Millas una cuestión que solamente se constituye teniendo presente el plano de la experiencia, pues, para sustituirla, se requiere otra instancia: la instancia de las estructuras formales, conceptuales, mentales, organizativas, subjetivas, las "operaciones del entendimiento":

Pero no queda agotada así el tema del conocimiento. Aunque el término alude primariamente y fundamentalmente a ciertas relaciones privilegiadas del pensamiento con las cosas, alude también a la organización del pensamiento, a ciertas relaciones internas del pensamiento consigo mismo (op. cit., tomo I, p. 99).

Una de las relaciones internas capitales, una de las operaciones organizativas del entendimiento a las que alude Millas, y con ello asume buena parte de la filosofía del conocimiento del siglo XX hasta aquí, es la lógica, el orden inferencial como relación constituida del conocimiento, ordinario o científico. No toda inferencia puede ser considerada conocimiento, pero la inversa sí es verdadera: no parece haber un conocimiento sin que, en algún plano, haya una inferencia, de cualquier tipo que sea. Por ello Millas afirma, como se expresaba más arriba, que el mero percibir un objeto no constituye un saber. Ver el árbol verde no constituye un conocimiento; pero sí lo es si se logra incluir esa percepción en una idea más general, en que se asocia esta u otra propiedad, en lo cual interviene un proceso inferencial, estructural, de organización del pensar.

2 Kuhn publica La estructura de las revoluciones cientificas, 2006, Fondo de Cultura Económica, México, en 1962 (con un importante epílogo en 1969), por lo que Millas, con su texto de 1969, está insertado en la visión de la idea de mundo como interrelación conceptual. 
A este respecto cabe hacer hincapié en que Millas presenta una postura que retoma una visión antigua de la lógica y que hoy está siendo revalidada. La naturaleza de la lógica no ha sido concebida en su historia de manera siempre uniforme. En el origen de la disciplina, Aristóteles y los aristotélicos consideraban que la lógica era una herramienta, un organon, algo diferenciado de la filosofía y cuyo estudio debía ser propedéutico. Así se mantuvo por mucho tiempo, incluso hasta hoy, sobre todo y especialmente después de la revolución fregeana, en que ésta parece independizarse por completo como una ciencia formal, cuestión que hoy la filosofía de la lógica está revisando. Sin embargo, en los orígenes mismos hubo otra postura: la lógica no se consideró como herramienta independiente sino como parte misma de la filosofía. Ese fue el planteamiento de los estoicos, especialmente en su figura central, Crísipo de Solos. Millas sigue en esto la tradición estoica y no la aristotélica ni la fregeana respecto de la naturaleza de la lógica. Concibe la lógica plenamente como parte de la epistemología, no como algo paralelo que presta un cierto servicio a la reflexión; es parte misma de la reflexión filosófica. Así como el conocimiento empírico contiene las operaciones subjetivas para integrar esa experiencia y nos muestra la experiencia ausente, así la teoría del conocimiento contiene a la lógica. ${ }^{3}$ Los estoicos concebían la filosofía como un compuesto de tres disciplinas (aunque esta idea puede provenir de Jenócrates y Aristóteles, son los estoicos quienes desarrollan la tesis de la tripartición y la conciben como un todo en que ninguna de las partes es superior a la otra): física (ontología, se podría decir), ética y lógica, cada una con una función propia ${ }^{4}$.

En su obra, Jorge Millas toca todos los temas centrales de la teoría del conocimiento vigentes entonces bajo la óptica de la sustitución de la experiencia; pero, además, en algunos, como es el de la relación entre epistemología y lógica, ofrece una perspectiva adelantada a su tiempo.

3 Véase J. Gould, 1970, The Philosophy of Chrysippus, State University of New York Press, Albany, pp. 45 y ss.

$4 \quad$ Véase Diógenes Laercio L. VII, 39,41, quien refiere las diferentes metáforas para explicar la tripartición. 